Original Research Article

\title{
Assessment of the knowledge, attitude and practice of self medication among second year undergraduate medical students in a tertiary care teaching hospital
}

\author{
Seema Gupta, Kanika Khajuria*, Nusrat K. Bhat, Vijay Khajuria, Akanksha Mehra
}

Department of Pharmacology, Government Medical College, Jammu, Jammu and Kashmir, India

Received: 09 March 2019

Revised: 26 March 2019

Accepted: 03 April 2019

*Correspondence to:

Dr. Kanika Khajuria,

Email: kanukhaj@gmail.com

Copyright: (C) the author(s), publisher and licensee Medip Academy. This is an openaccess article distributed under the terms of the Creative Commons Attribution NonCommercial License, which permits unrestricted noncommercial use, distribution, and reproduction in any medium, provided the original work is properly cited.

\begin{abstract}
Background: Inappropriate self-medication is a cause of concern as it can result in wasteful expenditure, prolonged suffering, drug dependence, resistance and increase in morbidity. Self medication assumes significance among medical students as they have knowledge about ailments and medicines. The aim of the study was to assess the knowledge, attitude and practice of self-medication among undergraduate medical students.

Methods: The present study was conducted in December 2017 among second professional undergraduate medical students in the Department of Pharmacology and Therapeutics, GMC Jammu after obtaining approval from the Institutional Ethics Committee of GMC, Jammu. A total of 123 students who took selfmedication during last six months were included and given a questionnaire that included open and close ended questions about self-medication. Data was analysed using Microsoft Excel and presented as number and percentages.

Results: Total of 123 second professional undergraduate MBBS students were analysed. $72(58.53 \%)$ were males and $51(41.46 \%)$ were females. $96(78 \%)$ students practised self-medication. Allopathic drugs were most commonly used for self medication (93.5\%), followed by Ayurvedic drugs. Fever and headache were common ailments treated with self medication. Common class of drugs used for self medication were antipyretics (66.6\%), antibiotics (42.2\%). Adverse drug reactions were perceived as the most common disadvantage of self medication. Analysis of source of information revealed that old prescriptions (33\%), internet $(18 \%)$ were the main sources of information. Regarding prevention of self medication, many students perceived that enhancing awareness was the most effective solution $(72.3 \%$ ) followed by stoppage of supply of medicines without prescription $(39.8 \%)$.

Conclusions: Self medication is practised by a majority of students. As responsible self medication is now increasingly being considered as a component of self-care, there is need for review of educational programs especially teaching of rational and judicious use of medicines to the undergraduate medical students.
\end{abstract}

Keywords: Attitude, Knowledge, Medical students, Practice, Self medication

\section{INTRODUCTION}

In economically deprived countries most episodes of illness are treated by self-medication. ${ }^{1}$ In some of the developing countries many drugs are dispensed over the counter without medical supervision. Self medication provides a lower cost alternative for people who cannot afford the cost of clinical service. ${ }^{2}$

Self-medication is defined as obtaining and consuming drugs without the advice of a physician either for diagnosis, prescription or surveillance of treatment. ${ }^{3}$ 
Self-medication involves acquiring medicines without a prescription, resubmitting old prescriptions to purchase medicines, sharing medicines with relatives or members of one's social circle or using leftover medicines stored at home. $^{4}$

WHO underscores importance of self-medication, provided medicines used are of proven safety, quality and efficacy, and indicated for conditions that are selfrecognizable. ${ }^{5}$

The prevalence rates of self-medication are high all over the world recorded up to $68 \%$ in European countries, while it is much higher in the developing countries with rates as high as $92 \%$ in Kuwait, $76 \%$ in Pakistan, 59\% in Nepal and $52 \%$ in India. ${ }^{6}$

Self-medication has both advantages and disadvantages. Appropriate self-medication relieves acute problems and it is time saving and economical, relieves the burden on the health care professionals. However, inappropriate selfmedication can result in wasteful expenditure, drug dependence, prolonged suffering, increase in morbidity due to adverse events, side effects and development of resistance to antibiotics.

Many factors influence self-medication like socioeconomic factors, lifestyle, and the increased potential to manage certain illnesses through self-care, greater availability of medicinal products, and availability of healthcare and health professionals, exposure to advertisement; education and professional status. ${ }^{7}$

In contrast to general public medical students are more likely to be influenced towards practice of self-medication. They have easy access to information from various sources to self-diagnose and self-medicate. ${ }^{8}$ The practice of selfmedication is very common among the health professional students who are more exposed to the knowledge of different drugs during their training period as compared to general population. The studies have reported high prevalence ranging from $57.7 \%$ to $76 \%$. $^{9}$

Though there are number of studies exploring selfmedication among general population, including university students, but there is a paucity of studies on selfmedication among medical students especially in our region. Therefore, it was thought worthwhile to study the extent of self-medication among medical students.

The aim of the present study was to assess the knowledge, attitude and practice of self-medication among Second professional undergraduate medical students.

\section{METHODS}

The present prospective, cross-sectional, questionnairebased study was conducted among 123 second professional undergraduate medical students of Government Medical College Jammu in the Department of
Pharmacology and Therapeutics to assess the knowledge, attitude, and practice regarding the self-medication. Ethical committee approval was obtained from the Institutional Ethics Committee prior to the commencement of the study.

All the students were briefly explained about the type and purpose of the study and informed that participation shall be voluntary, and their collected information would not be shared and would be anonymous.

\section{Inclusion criteria}

The second professional undergraduate medical students of either gender, who took self-medication during last six months were included and informed consent was taken from them.

\section{Exclusion criteria}

Students not willing to give consent were excluded from study

Written informed consent was obtained from each volunteer prior to the study. Students were administered a self-developed questionnaire that included both open and close ended questions regarding knowledge, attitude and practice of self-medication. This final validated questionnaire written in English comprised of 22 questions. The students were instructed to record their responses without consulting fellow students or resources like books etc.

Any event of use of over the counter (OTC) or prescription medicines without consulting a doctor was considered as self-medication. World Health Organization (WHO) defines Self medication as "the use of drugs to treat self diagnosed disorders or symptoms or the intermittent or continued use of prescribed drugs for chronic or recurrent disease or symptoms." 10

\section{Statistical analysis}

The data was analysed using Microsoft Excel and results were expressed by descriptive statistics such as counts and percentages.

\section{RESULTS}

A total of 123 Second professional undergraduate medical students included in the study were analysed for practice, attitude and knowledge about self-medication. 72 (58.53\%) were males and $51(41.46 \%)$ were females. The mean age of students was $19.5 \pm 1.22$ years. $96(78 \%)$ out of 123 students practised self-medication.

Allopathic drugs were most commonly used for self medication $(93.5 \%)$ followed by Ayurveda and homeopathy (Figure 1). 


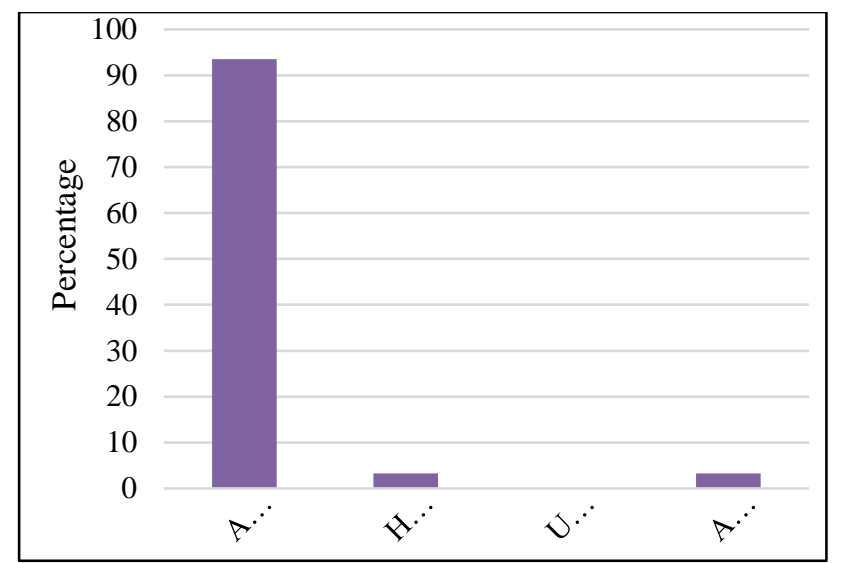

Figure 1: System of medicine followed for self medication.

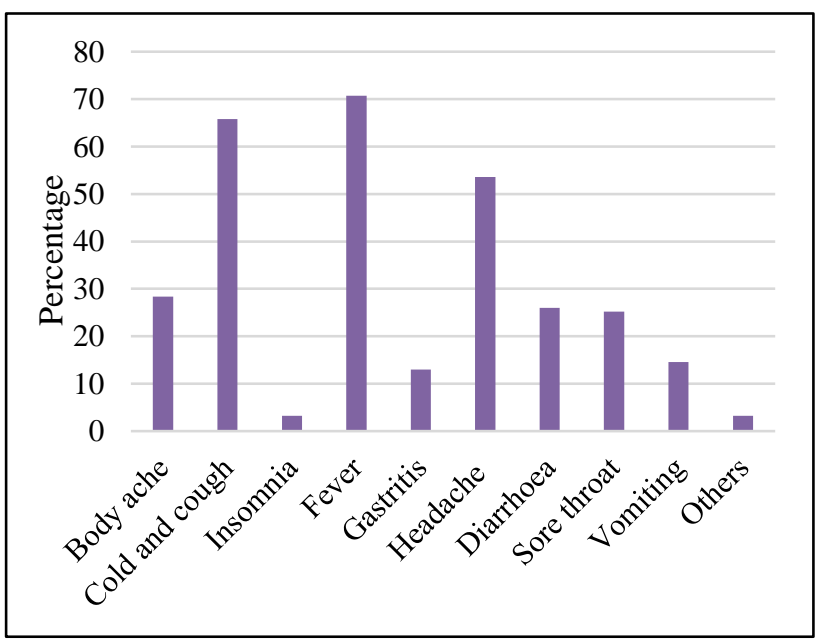

Figure 2: Indications for self medication.

Fever, headache, upper respiratory tract ailment and body aches were common ailments for which self medication was taken (Figure 2). Most common class of drugs used for self medication was antipyretics $(66.6 \%)$ followed by Antibiotics (42.2\%), Analgesics (39\%) and Antacids (38.2\%) (Figure 3).

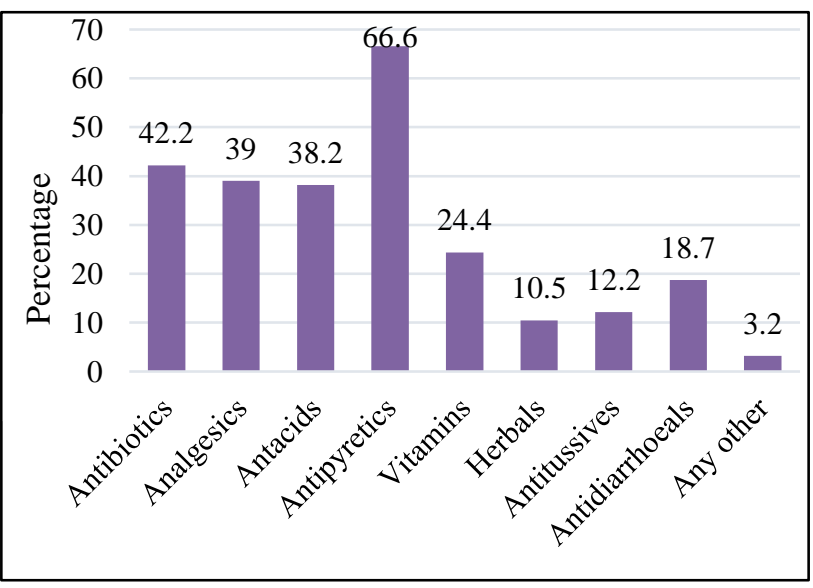

Figure 3: Categories of drugs used for self medication.
Attitude of students regarding immediate response on falling sick revealed that $66 \%$ of students preferred self medication and only $34 \%$ favoured physician consultation. (Figure 4).

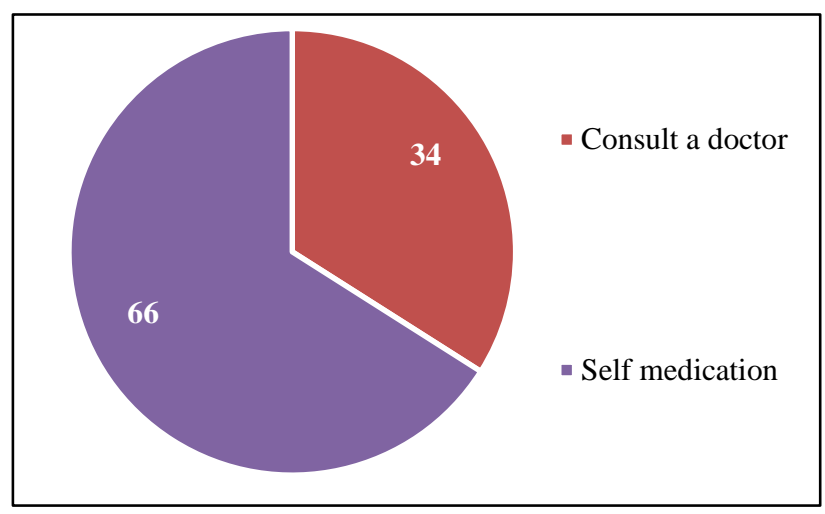

Figure 4: Immediate response of the students on falling sick.

Analysis of source of knowledge regarding self medication revealed that old prescriptions $(33 \%)$, followed by internet $(18 \%)$, text books $(15 \%)$ and teachers $(14 \%)$ were amongst the main sources for gathering information (Figure 5).

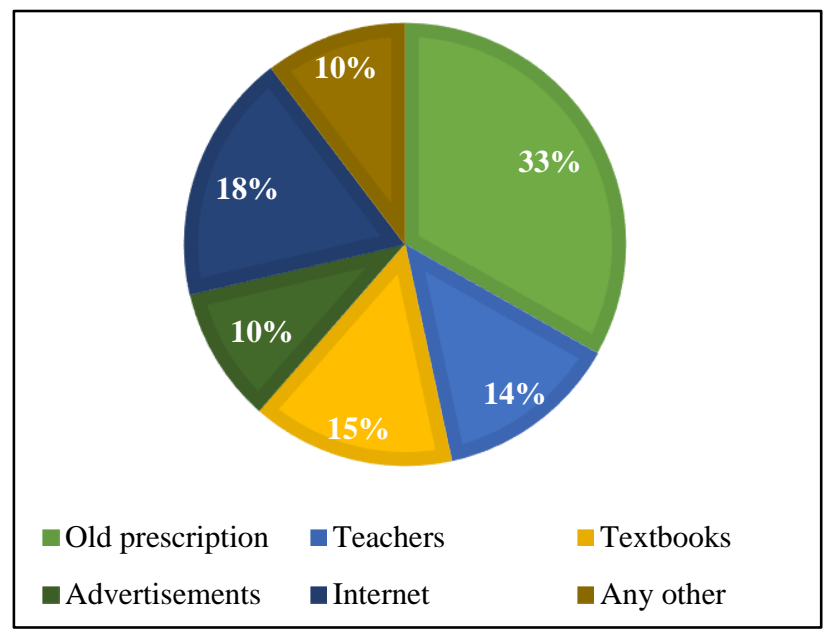

Figure 5: Source of information.

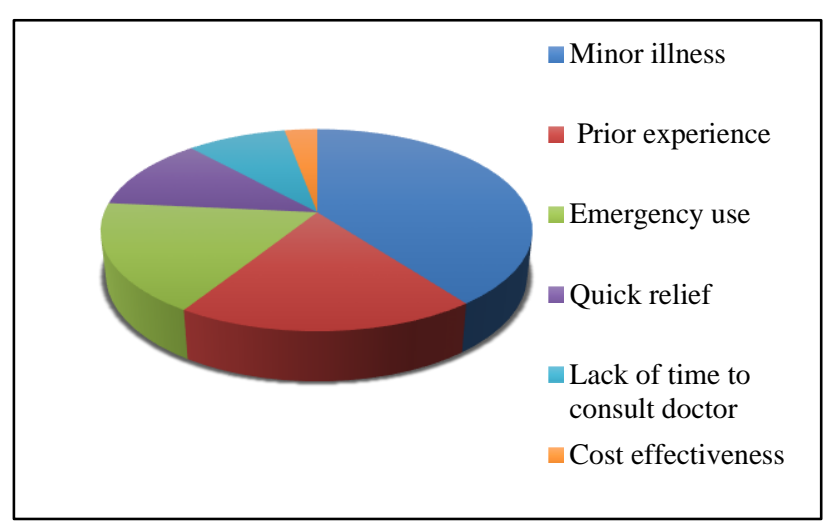

Figure 6: Reasons for self medication. 
Independent management of minor illness was perceived as the major merit of self medication (Table 1) and adverse drug reactions was considered to be the most common disadvantage of self medication followed by wrong diagnosis, risk of missing actual diagnosis and drug dependence (Table 1).

Table 1: Merits and demerits of self medication.

\begin{tabular}{|ll|}
\hline Merits of self medication & Percentage \\
\hline $\begin{array}{l}\text { Independent management of minor } \\
\text { illnesses }\end{array}$ & 91 \\
\hline Reduced pressure on medical services & 4 \\
\hline $\begin{array}{l}\text { Enables patients to control chronic } \\
\text { conditions }\end{array}$ & 4 \\
\hline Benefit to pharmaceutical companies & 1.6 \\
\hline Demerits of self medication & \\
\hline Risk of adverse drug reaction & 80.5 \\
\hline Risk of using wrong diagnosis & 44.7 \\
\hline Risk of missing actual diagnosis & 35.7 \\
\hline Risk of drug dependence & 27.6 \\
\hline
\end{tabular}

Most important reason for self medication was treatment of minor illness (40\%) and their past experience in treatment of the condition (19\%) (Figure 6).

Regarding prevention of self medication, most of the students perceived that enhancing awareness regarding implications of self medication was most effective solution $(72.3 \%)$ followed by stoppage of supply of medicines without prescription $(39.8 \%)$, strictly implementing laws regarding pharmaceutical advertisements (22.7\%) and increasing health care availability (5\%), while $3 \%$ did not give any opinion (Figure 7 ).

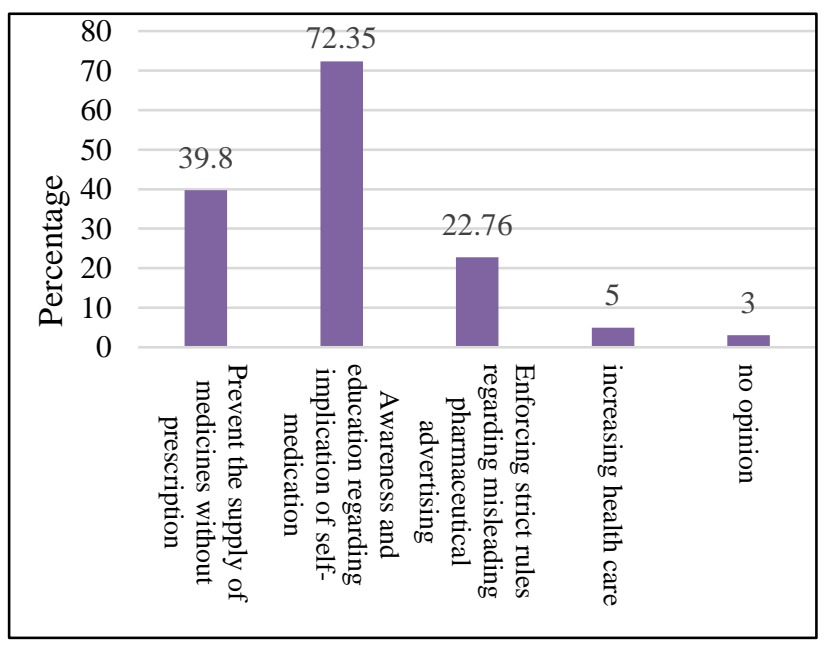

Figure 7: Methods to prevent growing trends of self medication.

\section{DISCUSSION}

Self medication is worldwide and can be beneficial or even detrimental to the health. On one hand it provides prompt treatment, saves money and time, allows health professionals to devote their more attention to serious ailments, but on other hand inappropriate therapy can result in economic loss, adverse reactions, failure and resistance. So, it is difficult to provide a simple answer whether it should be promoted or not.

WHO has also highlighted the importance of self medication. It assumes importance in countries where scarcity of health resources are present. Self medication is prevalent in self diagnosed common ailments or in chronic or recurrent disorders which were initially diagnosed by doctors and require prolonged treatment as it saves patients from long queues at hospitals. However, medicines with established efficacy, safety, quality and availability over the counter should be taken.

Among population, the medical students have more access to the medicines. Medical students are future doctors and acquire knowledge about prescribing of medicines for various ailments particularly during their second professional course. It makes them a special group that is prone for self medication. Therefore the present study was aimed to determine the second year medical students' knowledge, attitude and perception regarding self medication and to have a deeper insight.

In the current study, there were 123 students which comprised of $58.53 \%$ males and $41.46 \%$ females. $96(78 \%)$ students practised self-medication. This suggests that self medication is quite prevalent among medical students. High prevalence of Self-medication practice among undergraduate have also been documented in past by numerous studies in India in agreement to our results. ${ }^{11-14}$

Most studies have shown females outnumbering males unlike our results. But in some studies though females outnumbered males but the difference was not statistically significant. ${ }^{15,16}$ However, some trials have recorded more males indulged in in self medication as observed by us. ${ }^{17}$ Gender is observed as important factor in young people especially students indulging in self medication. ${ }^{18-20}$ Most of these studies were done in final term medical students, while we have carried out our study in second professional students.

Allopathic drugs were most commonly used for self medication $(93.5 \%)$ followed by Ayurveda and homeopathy. This is quite understandable as the students were more well versed with allopathic medicines than other. Similar findings have also been reported earlier by various authors. ${ }^{19,21,22}$

Antipyretics were most commonly used $(66.6 \%)$ followed by Antibiotics (42.2\%), Analgesics (39\%), Antacids (38.2\%). Surprisingly, the commonly perceived notion regarding over use of vitamins was only $24.4 \%$. Present study findings are in concurrence with results of number of studies conducted earlier. ${ }^{17,21}$ The more number of responses in favour of antipyretic/ analgesic and antibiotics 
in the present study can be explained as fever was the most common ailment treated with self medication, followed by cold or headache. Higher use of antibiotics as self medication has also been recorded by various research workers. ${ }^{11,19,20,23-25}$

Attitude of students regarding immediate response on falling sick revealed that $66 \%$ of students preferred self medication and only $34 \%$ favoured physician consultation. This may be overrated as student's newly acquired knowledge may be a contributory factor.

Analysis of source of knowledge regarding self medication revealed that old prescriptions, text books and teachers contributed in majority and this was in one way or the other related to their study course. Internet was a major source for information even with medical students. These findings are in concurrence with earlier reports which have also shown previous old prescriptions, text books as major source of information. ${ }^{12,14,21}$ The findings of current study do underline the shift in trends from the traditional teacher to inclination towards internet. Such a scenario calls for frequent evaluation from time to time to have insight in changing pattern of society.

Students perception regarding merits of self medication showed that independent management of minor illness was the major merit while adverse drug reactions, risk of wrong diagnosis, missing diagnosis and drug dependence were perceived as demerits of self medication. In present study, the most common reason of self medication was that that they thought the illness was too trivial for consultation (40\%) followed by a prior experience (19\%). These results are similar to a previous report. ${ }^{19}$

Regarding prevention of self medication, most of students in the current study perceived that enhancing awareness regarding implications of self medication was the most effective solution (72.3\%) followed by stoppage of supply of medicines without prescription (39.8), strictly implementing laws regarding pharmaceutical advertisements $(22.7 \%)$ and increasing health care availability (5\%). Similar to present study observations, increasing awareness has been recorded as major perceived preventive measure14, while preventing supply the drugs without prescription as major measure. ${ }^{19}$

Though present study has shown prevalence of self medication in medical undergraduate students but self care can be only justified when there is a rational use of medicines while inappropriate self use of medicines can be harmful.

The findings of the current study are based on the evaluation of second professional medical students in a single centre which remains a limitation, further trials need to be conducted among other professional medical students to have a better understanding of the practice of selfmedication. Although the students were encouraged to fill the questionnaires independently, but mutual influence cannot be ruled out.

\section{CONCLUSION}

Self medication is practised by a majority of students. (78\%). Allopathic drugs were most commonly used with antipyretic drugs $(66.6 \%)$ being the lead group of drugs. Old prescription and internet were the major information sources used by the students. As responsible self medication is now increasingly being considered as a component of self-care, there is a need for review of educational programs especially teaching of rational and judicious use of medicines to the undergraduate medial students. More multicentric studies need to be undertaken among medical students and general population to understand the factors influencing self medication in India.

\section{Funding: No funding sources}

Conflict of interest: None declared

Ethical approval: The study was approved by the Institutional Ethics Committee of Government Medical College Jammu, India (vide no. $I_{2} C / 2018 / 532$ )

\section{REFERENCES}

1. Geissler PW, Nokes K, Prince RJ, Achieng'Odhiambo R, Aagaard-Hansen J, Ouma JH. Children and medicines: self-treatment of common illnesses among Luo schoolchildren in western Kenya. Soc Sci Med. 2000;50(12):1771-83.

2. Hussain S, Malik F, Hameed A, Ahmad S, Riaz H. Exploring health seeking behavior, medicine use and self medication in urban and rural Pakistan. Southern Med Review. 2010;3(2):32-5.

3. Dilie A, Gualu T, Haile D, Zuleta FA. Knowledge, attitude and practice of self-medication among health science students at Debre Markos university, Northwest Ethiopia. J Public Health Epidemiol. 2017;9(5):106-13.

4. Loyola Filho AI, Lima-Costa MF, Ucho^a E. Bambu1' Project: a qualitative approach to self- medication. Cad Saude Publica. 2004;20(6):1661-9.

5. WHO Resource. The role of the pharmacist in selfcare and self-medication. Responsible selfmedication, 1998. Available at: http://www.apps.who.int/medicinedocs/en/d/ Jwhozip32e/3.3.html. Accessed 15 October 2014.

6. Patel P, Prajapati A, Ganguly B, Gajjar B. Study on impact of pharmacology teaching on knowledge, attitude and practice on self-medication among medical students. Int $\mathrm{J}$ Med Sci Public Health. 2013;2(2):181-6.

7. Sontakke SD, Bajait CS, Pimpalkhute SA, Jaiswal KM, Jaiswal SR. Comparative study of evaluation of self-medication practices in first and third year medical students. Int J Biol Med Res. 2011;2(2):5614.

8. Badiger S, Kundapur R, Jain A, Kumar A, Pattanshetty S, Thakolkaran N, et al. Self- medication 
patterns among medical students in South India. Australas Med J. 2012;5(4):217-20.

9. Pandya RN, Jhaveri KS, Vyas FI, Patel VJ. Prevalence, pattern and perceptions of selfmedication in medical students. Int $\mathrm{J}$ Basic Clin Pharmacol. 2013;2(3):275-80.

10. Singla S, Kaur M, Mahajan R. Pattern and practice of self medication in students of health professional university in North India. Int J Basic Clin Pharmacol. 2017;6(11):2607-11.

11. Self-medication popular among medical students: AIIMS study. Available at: http://www.livemint.com/Politics/XcN44QD5g8aW4 dwltcUdtI/Selfmedicationpop ular-among-medicalstudents-AIIMS-study.html. Accessed 2013 Feb 27.

12. Patil SB, Vardhamane SH, Patil BV, Santoshkumar J, Binjawadgi AS, Kanaki AR. Self-medication practice and perceptions among undergraduate medical students: a cross-sectional study. J Clin Diag Res. 2014 Dec;8(12):HC20.

13. Klemenc-Ketiš Z, Hladnik Ž, Kersnik J. A cross sectional study of sex differences in self-medication practices among university students in Slovenia. Collegium Antropologicum. 2011;35(2):329-34.

14. Raju GN, Manjunath SM, Dharmaraj B. A cross sectional study on the practise of self-medication among 2nd year medical and dental students. Indian J Pharma Pharmacol. 2016;3(4):165-8.

15. Seam M, Bhatta R, Saha B, Das A, Hossain M, Uddin S, Karmakar P, Choudhuri M, Sattar M. Assessing the perceptions and practice of self-medication among Bangladeshi undergraduate pharmacy students. Pharmacy. 2018;6(1):6.

16. Thadani S, Salman MT, Ahamed A. Knowledge attitude and practice of self medication among second year undergraduate medical students. J Ration Pharmacother Res. 2013;1(3):131-4.

17. Kumar N, Kanchan T, Unnikrishnan B, Rekha T, Mithra P, Kulkarni V, et al. Perceptions and practices of self-medication among medical students in coastal South India. PloS One. 2013;8(8):e72247.
18. Banerjee I, Bhadury T. Self-medication practice among undergraduate medical students in a tertiary care medical college. West Bengal J Postgrad Med. 2012;58(2):127-31.

19. Verma RK, Mohan L, Pandey M. Evaluation of selfmedication among professional students in North India: proper statutory drug control must be implemented. Asian J Pharmaceutical Clinical Res. 2010;3(1):60-4.

20. Gupta V, Bansal P, Manhas R, Singh Z, Ghaiye P. Preferred system of medicine and reasons of self medication among college students in Malwa region of Punjab. Journal of Drug Delivery and Therapeutics. 2011;1(2):27-9.

21. Abay SM, Amelo W. Assessment of Self-medication practices among medical, pharmacy, health science students in Gondar University, Ethiopia. J Young Pharmacists. 2010;2(3):306-10.

22. Ali SE, Ibrahim MI, Palaian S. Medication storage and self-medication behaviour amongst female students in Malaysia. Pharma Pract. 2010;8(4).

23. El Ezz NF, Ez-Elarab HS. Knowledge, attitude and practice of medical students towards self medication at Ain Shams University, Egypt. J Preventive Med Hyg. 2011 Dec 4;52(4).

24. Fadare JO, Tamuno I. Antibiotic self-medication among university medical undergraduates in Northern Nigeria J Public Health Epidemiol. 2011;3(5):217-20.

25. Kayalvizhi S, Senapathi R. Evaluation of the perception, attitude and practice of self-medication among business students in 3 select cities, South India. Int J Enterprise Innov Manag Studies. 2010;1(3):40-4.

Cite this article as: Gupta S, Khajuria K, Bhat NK, Khajuria V, Mehra A. Assessment of the knowledge, attitude and practice of self medication among second year undergraduate medical students in a tertiary care teaching hospital. Int $\mathrm{J}$ Basic Clin Pharmacol 2019;8:1090-5. 